\title{
Coverage, Affordability, and Care for Low-Income People with Diabetes: 4 Years after the Affordable Care Act's Medicaid Expansions
}

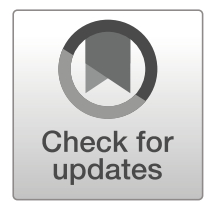

\author{
Dahai Yue, $M S^{7}$, Yuhui Zhu, $M S^{2}$, Petra W. Rasmussen, $M P H^{7}$, James Godwin, $B A^{7}$, and \\ Ninez A. Ponce, $P h D^{7,3}$ \\ 'Department of Health Policy and Management, University of California Los Angeles Fielding School of Public Health, Los Angeles, CA, USA; \\ ${ }^{2}$ Department of Epidemiology, University of California Los Angeles Fielding School of Public Health I, Los Angeles, CA, USA; ${ }^{3}$ Department of Health \\ Policy and Management, UCLA Center for Health Policy Research, UCLA Fielding School of Public Health, Los Angeles, CA, USA.
}

KEY WORDS: diabetes; Medicaid expansions; access to care; disparities.

J Gen Intern Med 35(7):2222-4

DOI: $10.1007 / \mathrm{s} 11606-019-05614-2$

(c) Society of General Internal Medicine 2020

\section{INTRODUCTION}

Diabetes is one of the most common and expensive diseases in the USA. Although the positive impact of the Affordable Care Act (ACA)'s Medicaid expansions on insurance coverage, access, and health have been extensively studied in the general population, ${ }^{1,2}$ the extent to which the ACA Medicaid expansions affect people with diabetes is unclear. These studies have used a smaller subsample of states and have focused only on the years immediately after the ACA Medicaid expansions. ${ }^{3-5}$ There is less evidence on the longer term effects of the ACA on patients with diabetes. ${ }^{6}$ A study of the nationwide impact of the ACA's Medicaid expansions on health care access, affordability, and care contributes to the literature on healthcare access among those with diabetes, and to the policy debates on Medicaid reforms.

\section{METHODS}

We use data from 2011 to 2017 Behavioral Risk Factor Surveillance System (BRFSS) and compare residents in 24 Medicaid expansion states (Alaska, Arizona, Arkansas, Colorado, Connecticut, Hawaii, Illinois, Indiana, Iowa, Kentucky, Maryland, Michigan, Minnesota, Nevada, New Hampshire, New Jersey, New Mexico, North Dakota, Ohio, Oregon, Pennsylvania, Rhode Island, Washington, and West Virginia) with those in 20 non-expansion states (Alabama, Florida, Georgia, Idaho, Kansas, Louisiana, Maine, Mississippi, Missouri, Nebraska, North Carolina, Oklahoma, South Carolina, South

Received October 3, 2019

Revised October 22, 2019

Accepted December 9, 2019

Published online January 2, 2020
Dakota, Tennessee, Texas, Utah, Virginia, Wisconsin, and Wyoming) using a difference-in-differences (DD) approach.

The analytic sample includes low-income nonelderly BRFSS respondents (income less than or equal to $138 \%$ Federal Poverty Level, ages 19-64) who reported having ever been told that they have diabetes in the 2011 to 2017 BRFSS. Respondents reporting pre-diabetes and borderline diabetes, or gestational diabetes, were excluded. To reveal possible changes in policy effects across the years, we fit two sets of models. The first set considers 2015 and 2016 as the early post-expansion period (year 2 and 3 effect), while the second set uses data from 2017 as the later post-expansion period (year 4 effect). All models control for the following variables: age, gender, educational attainment, language of interview, employment status, marital status, race/ethnicity, self-reported health, income level, number of children in the household, number of adults in the household, state and year-quarter fixed effects, and state annual unemployment rates. Multiple imputations and survey weights are applied using Stata, version 14.2 (StataCorp).

\section{RESULTS}

The final sample includes 16,666 respondents from expansion states and 19,176 respondents from non-expansion states. Characteristics of individuals between the two groups are similar. Unadjusted temporal trends of outcomes are displayed in Figure 1. Estimates from difference-in-differences analyses are documented in Table 1. The year 2 and 3 effect of the expansions on health insurance coverage is 7.0 percentage points (pp) (95\% CI, 3.1 to 10.8), and is $6.2 \mathrm{pp}(95 \% \mathrm{CI}$, 2.0 to 10.4 ) on having no financial barriers to care. However, the effects decreased and became insignificant in 2017. The year 4 effect $(3.2 \mathrm{pp})$ of receiving a routine annual checkup is larger than the year 2 and 3 effect $(2.7 \mathrm{pp})$, but still insignificant. While non-Hispanic whites saw continued gains in health insurance coverage ( $9.5 \mathrm{pp}$ in year 2 and 3 , and $7.0 \mathrm{pp}$ in year 4) and significant increases in routine checkups in year 4 (7.9 pp), blacks and Hispanics did not. 

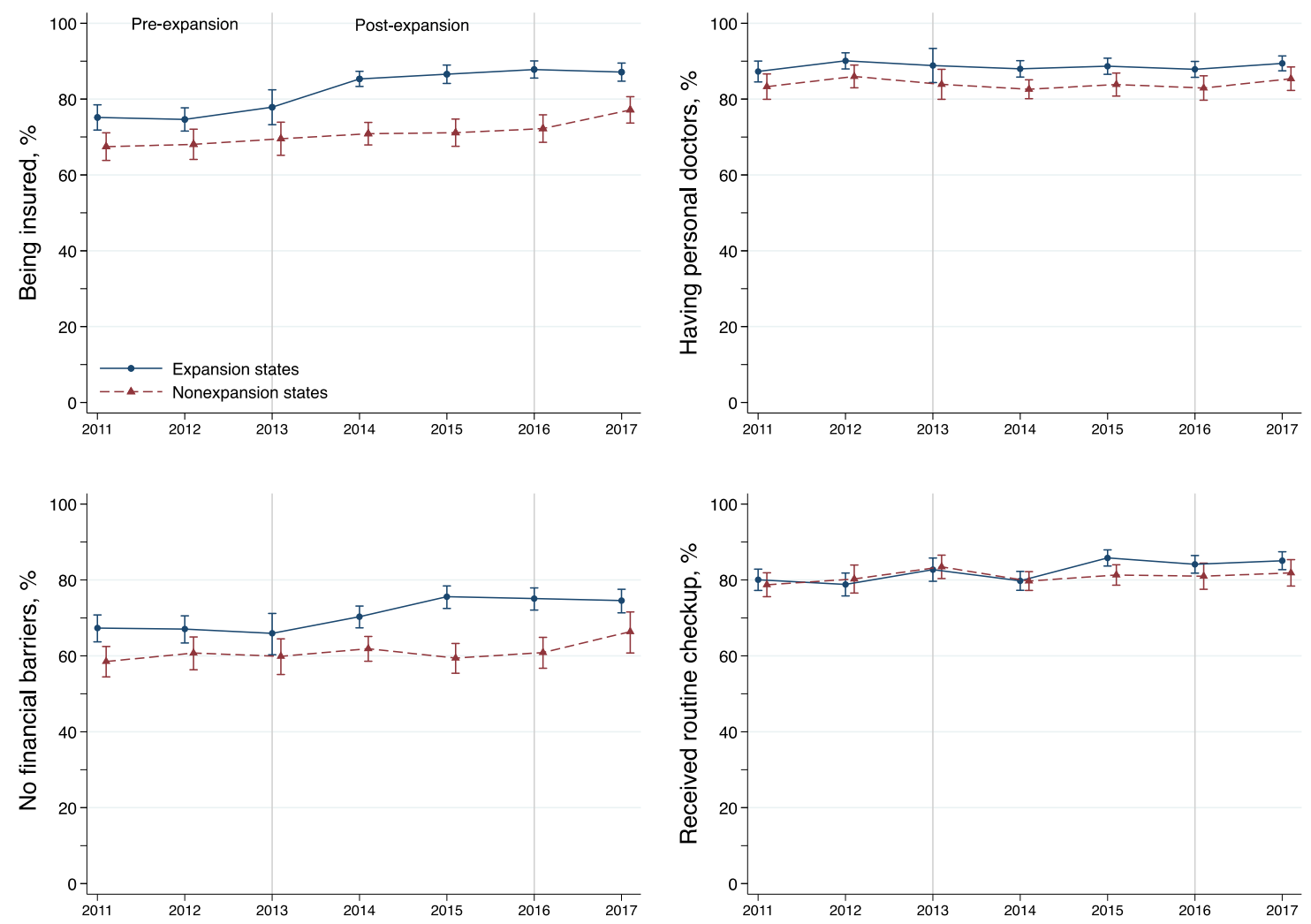

Notes: Estimates are based on low-income nonelderly patients with diabetes in the BRFSS data. Multiple imputations were used to account for missing values and survey weights were used to adjust for complex survey design. The pre-expansion period includes 2011-2013 and indicates plausible parallel trends between the two groups.

Figure 1 Trajectory of outcomes by expansion and non-expansion states from 2011 to 2017

\section{DISCUSSION}

The ACA increased coverage and affordability for people with diabetes immediately after the ACA Medicaid expansions, but not after 2016. Closing the coverage and affordability gaps in expansion versus non-expansion states was largely driven by improvements in non-expansion states. Despite this "catch up," in 2017, healthcare coverage was still 10 pp lower and affordability was 8 pp lower among diabetics in states that decided against expanding Medicaid. Although there were favorable ACA effects for all racial/ethnic groups, our study suggests that non-Hispanic whites benefitted more from the expansions.
Our study offers new evidence on the coverage, affordability, and care for a vulnerable patient group over the early and later years of implementation of the Medicaid expansions under the Affordable Care Act. Future research and practice are warranted on eliminating racial/ethnic disparities, and exploring what drives recent gains in coverage and affordability for low-income diabetic patients from the non-expansion states. These insights could contribute to improving the health and well-being of the over 30 million people with diabetes across the nation. 
Table 1 Changes in Coverage, Affordability, and Care Among Low-Income Nonelderly People with Diabetes, by Race/Ethnicity Groups

\begin{tabular}{|c|c|c|c|c|}
\hline & \multicolumn{2}{|l|}{ Year 2 and 3 effect } & \multicolumn{2}{|l|}{ Year 4 Effect } \\
\hline & DD (percentage point) & $p$ Value & DD (percentage point) & $p$ Value \\
\hline \multicolumn{5}{|l|}{ All racial/ethnic groups } \\
\hline Health insurance coverage & 7.0 & $<0.001$ & 2.4 & 0.33 \\
\hline No financial barriers to accessing care & 6.2 & 0.004 & 1.1 & 0.71 \\
\hline Having personal doctors & -0.2 & 0.91 & 0.6 & 0.76 \\
\hline Routine checkups & 2.7 & 0.13 & 3.2 & 0.17 \\
\hline$N$ & & 29,932 & & 23,303 \\
\hline \multicolumn{5}{|l|}{ Non-Hispanic whites } \\
\hline Health insurance coverage & 9.5 & $<0.001$ & 7.0 & 0.008 \\
\hline No financial barriers to accessing care & 7.4 & 0.007 & 2.9 & 0.42 \\
\hline Having personal doctors & -2.5 & 0.18 & 1.7 & 0.38 \\
\hline Routine checkups & 4.1 & 0.06 & 7.9 & 0.008 \\
\hline$N$ & & 16,569 & & 12,953 \\
\hline \multicolumn{5}{|l|}{ Non-Hispanic blacks } \\
\hline Health insurance coverage & 2.5 & 0.50 & -6.2 & 0.22 \\
\hline No financial barriers to accessing care & 0.9 & 0.84 & -3.5 & 0.53 \\
\hline Having personal doctors & 2.1 & 0.53 & 3.5 & 0.37 \\
\hline Routine checkups & -1.0 & 0.75 & 2.3 & 0.57 \\
\hline$N$ & & 6542 & & 5062 \\
\hline \multicolumn{5}{|l|}{ Hispanics } \\
\hline Health insurance coverage & 7.7 & 0.17 & -1.8 & 0.80 \\
\hline No financial barriers to accessing care & NA & NA & NA & NA \\
\hline Having personal doctors & 3.2 & 0.54 & -1.7 & 0.80 \\
\hline Routine checkups & 2.9 & 0.57 & -6.3 & 0.34 \\
\hline$N$ & & 3734 & & 2764 \\
\hline \multicolumn{5}{|l|}{ Other race/multiracial races } \\
\hline Health insurance coverage & -0.2 & 0.97 & 0.4 & 0.96 \\
\hline No financial barriers to accessing care & NA & NA & NA & NA \\
\hline Having personal doctors & NA & NA & NA & NA \\
\hline Routine checkups & -3.3 & 0.51 & 8.9 & 0.16 \\
\hline$N$ & & 2987 & & 2502 \\
\hline
\end{tabular}

Notes: $D D=$ Difference-in-Differences expressed as percentage point change. All statistics of outcomes by expansion states and non-expansion states were from weighted analyses of BRFSS respondents who are low-income, nonelderly diabetic adults. $N$ represents the number of observations in the subpopulation of analysis from multiple imputations. 2011-2013 were used as pre-ACA periods, while 2015-2017 were for post-ACA years. Results from analyses violating the parallel assumption of difference-in-difference analyses were not reported and denoted as "NA." "Other Race" includes American Indian or Alaskan Native, Asian, Native Hawaiian or other Pacific Islander, and other race groups

Corresponding Author: Ninez A. Ponce, PhD; Department of Health Policy and Management, UCLA Center for Health Policy Research, UCLA Fielding School of Public Health, 10960 Wilshire Blvd, Suite 1550, Los Angeles, CA 90024, USA (e-mail: nponce@ucla.edu).

\section{Compliance with Ethical Standards:}

Conflict of Interest: The authors declare that they do not have a conflict of interest.

\section{REFERENCES}

1. Sommers BD, Blendon RJ, Orav EJ, Epstein AM. Changes in Utilization and Health Among Low-Income Adults After Medicaid Expansion or Expanded Private Insurance. JAMA Intern Med. 2016. doi:https://doi. org/10.1001/jamainternmed.2016.4419

2. Yue D, Rasmussen PW, Ponce NA. Racial/Ethnic Differential Effects of Medicaid Expansion on Health Care Access. Health Serv Res. 2018;53(5):3640-3656. doi: https://doi.org/10.1111/1475-6773.12834.
3. Angier H, Ezekiel-Herrera D, Marino M, Hoopes M, Jacobs EA, DeVoe JE, et al. Racial/Ethnic Disparities in Health Insurance and Differences in Visit Type for a Population of Patients with Diabetes after Medicaid Expansion. J Health Care Poor Underserved. 2019;30(1):116-130. doi: https://doi.org/10.1353/hpu.2019.0011.

4. Huguet N, Springer R, Marino M, Angier H, Hoopes M, Holderness $\mathbf{H}$, et al. The Impact of the Affordable Care Act (ACA) Medicaid Expansion on Visit Rates for Diabetes in Safety Net Health Centers. J Am Board Fam Med. 2018;31(6):905-916. doi:https://doi.org/10.3122/jabfm.2018.06. 180075.

5. Luo H, Chen ZA, Xu L, Bell RA. Health Care Access and Receipt of Clinical Diabetes Preventive Care for Working-Age Adults With Diabetes in States With and Without Medicaid Expansion: Results from the 2013 and 2015 BRFSS. J Public Health Manag Pract. 2018 Jun 20. doi: https://doi. org/10.1097/PHH.0000000000000832.

6. Kelley AT, Tipirneni R. Care for Undocumented Immigrants - Rethinking State Flexibility in Medicaid Waivers. New England Journal of Medicine. 2018;378(18):1661-3. doi:https://doi.org/10.1056/NEJMp1801871

Publisher's Note Springer Nature remains neutral with regard to jurisdictional claims in published maps and institutional affiliations. 